Article

\title{
Chemical Characterization and Antitumor Activities of Polysaccharide Extracted from Ganoderma lucidum
}

\author{
Zengenni Liang ${ }^{1}$, Youjin $\mathrm{Yi}^{2}$, Yutong Guo ${ }^{3}$, Rencai Wang ${ }^{1, *}$, Qiulong $\mathrm{Hu}^{1}$ and \\ Xingyao Xiong ${ }^{1, *}$
}

1 College of Horticulture and Landscape, Hunan Agricultural University, Changsha 410128, China; E-Mails: enni_007@163.com (Z.L.); huqiulongnet@126.com (Q.H.)

2 College of Food Science and Technology, Hunan Agricultural University, Changsha 410128, China; E-Mail: 13875946008@163.com

3 State Key Laboratory of Sub-Health Intervention Technology, State Administration of Traditional Chinese Medicine, Changsha 410128, China; E-Mail: gytyjj@126.com

* Authors to whom correspondence should be addressed;

E-Mails: xiongxy@hunau.net (X.X.); cavepeoper@gmail.com (R.W.);

Tel./Fax: +86-731-8467-3765 (X.X.).

Received: 19 March 2014; in revised form: 1 May 2014 / Accepted: 4 May 2014 /

Published: 22 May 2014

\begin{abstract}
Ganoderma lucidum polysaccharide (GLP) is a biologically active substance reported to possess anti-tumor ability. Nonetheless, the mechanisms of GLP-stimulated apoptosis are still unclear. This study aims to determine the inhibitory and apoptosis-inducing effects of GLP on HCT-116 cells. We found that GLP reduced cell viability on HCT-116 cells in a time- and dose-dependent manner, which in turn, induced cell apoptosis. The observed apoptosis was characterized by morphological changes, DNA fragmentation, mitochondrial membrane potential decrease, $\mathrm{S}$ phase population increase, and caspase- 3 and -9 activation. Furthermore, inhibition of c-Jun $N$-terminal kinase (JNK) by SP600125 led to a dramatic decrease of the GLP-induced apoptosis. Western blot analysis unveiled that GLP up-regulated the expression of Bax/Bcl-2, caspase-3 and poly (ADP-ribose) polymerase (PARP). These results demonstrate that apoptosis stimulated by GLP in human colorectal cancer cells is associated with activation of mitochondrial and mitogen-activated protein kinase (MAPK) pathways.
\end{abstract}

Keywords: human colon cancer cells; apoptosis; mitochondria; caspase; MAPK 


\section{Introduction}

Colorectal cancer (CRC) is a major public health problem that arises from the epithelium of the mucous membrane within the colon. It is the third most common cancer globally with a high mortality rate and an increasing incidence rate among young adults under 50 years of age [1,2]. Every year an estimated 8 million new cases of colorectal cancer are diagnosed, however, clinical trials with adjuvant chemotherapy have shown little improvement in survival rates, as well as the severe side effects [3]. In 2012, an estimated 143,460 colon and rectal cancer cases were diagnosed and 51,690 patients died from colorectal cancer in the United Stated [4].

Apoptosis is an ordered and orchestrated mechanism of cellular action that can be engaged by a range of cellular insults in physiology and pathology [5]. Neoplasm is a cell proliferative disorder and deregulation of apoptosis with multiple causes including both genetic and environmental factors [6]. Currently, radiotherapy, chemotherapy and immune regulation are considered as treatments that exert their effects by triggering cell apoptosis. Effective apoptotic activities induced by remedy have become a hallmark in cancer prevention [7]. Studies have shown that the enhancement of apoptosis following DNA damage prevents the development of colorectal cancer, which may prove to be a key mechanism of cancer treatment [8].

Ganoderma lucidum polysaccharide (GLP) from the extract of a basidiomycete fungus has been shown to significantly suppress tumorigenesis, viability, invasion and metastasis of several cancer cell lines by its cytotoxic and anti-angiogenic effects in vitro and in vivo [9]. GLP is also believed to have anti-tumor effects mediated by boosting host immune cells including macrophages, lymphocytes, natural killer cells and dendritic cells [10,11]. Furthermore, substantial reports support the belief that GLP possesses non-toxicity and reduced toxicity-related conditions due to chemotherapy/radiotherapy on normal cells [12]. These studies disclose that GLP may potentially serves as a chemopreventive agent for cancer therapy. To date the molecular mechanisms in GLP-induced HCT-116 cell apoptosis have not been characterized. This research investigated the effects of GLP on inhibitory and apoptotic reactions towards HCT-116 human colon cancer cells in vitro. Additionally, the regulation of GLP-induced apoptosis involving mitochondria, caspases and mitogen-activated protein kinase (MAPK) was explored.

\section{Results and Discussion}

\subsection{Yield, Purity and Characterization of Polysaccharide}

The yield, based on weight of the lyophilized crude water-soluble polysaccharide, was about 3.08\%. Figure 1 showed that polysaccharide fractions had no absorption at 260 and $280 \mathrm{~nm}$ in the UV spectrum, suggesting the absence of nucleic acid and protein. The total carbohydrate content and uronic acid analyses found that crude extract GLP was an acidic polysaccharide containing 89\% of total carbohydrate and $11 \%$ of uronic acid. The molecular weight composition of the polysaccharide is as follows: $10-30 \mathrm{kDa}, 32.1 \%$; $30-50 \mathrm{kDa}, 21.8 \%$; and $>50 \mathrm{kDa}, 46.1 \%$. The polysaccharide consists of arabinose, galactose, cellose and glucose in the molar ratios of 11:3:1:3.

IR spectra of GLP are depicted in Figure 2. The obvious polysaccharide at $3402 \mathrm{~cm}^{-1}$ was due to $\mathrm{O}-\mathrm{H}$ stretching vibration. The spectrum also showed an intense vibration and a water-related absorbance at $1633 \mathrm{~cm}^{-1}$. The peak-height at $1458 \mathrm{~cm}^{-1}$ was attributed to $\mathrm{C}-\mathrm{H}$ bending vibration. 
The absorption band towards $1109 \mathrm{~cm}^{-1}$ suggested that the peak was related to the stretching vibration of $\mathrm{C}-\mathrm{O}$. The absorption peak at $870 \mathrm{~cm}^{-1}$ was assigned to $\alpha$-type glycosidic linkages in the polysaccharide. Typical characteristic peaks were observed at both 847 and $922 \mathrm{~cm}^{-1}$ for $\alpha-1,4-D-g l u c a n$ [13]. Together with the high positive value of the specific rotation, the IR spectrum indicated the presence of $\alpha$-glycosidic linkages in the GLP.

Figure 1. The UV spectra of polysaccharide fractions of Ganoderma lucidum.

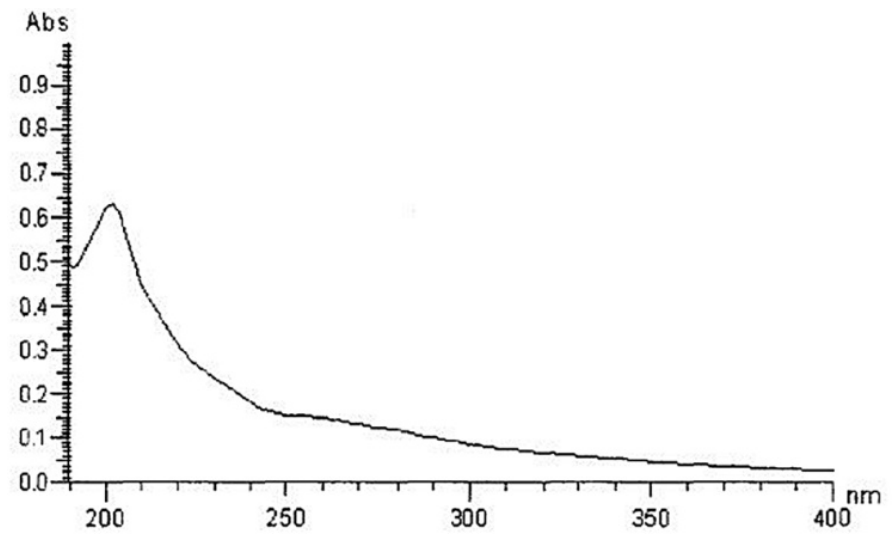

Figure 2. Infrared spectroscopy of Ganoderma lucidum polysaccharide (GLP).

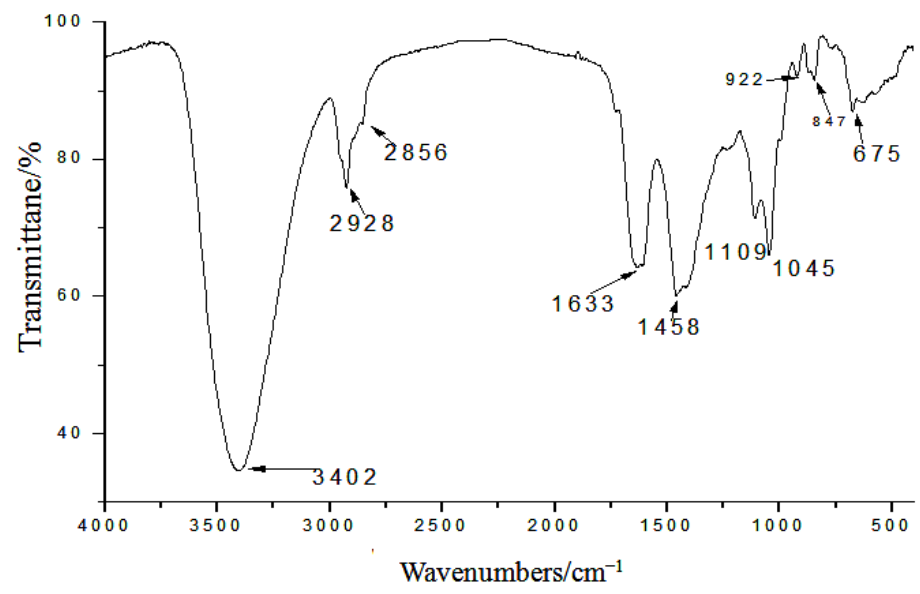

\subsection{Effects of Ganoderma lucidum Polysaccharide (GLP) on HCT-116 Cell Viability}

Many previous reports have indicated that Chinese herbs inhibit the growth of cancer through direct reactions to cell killing and/or indirect reactions that boost immunity function on cancer cells [14]. To investigate whether GLP had cytotoxic effects, cell viability was performed by MTT assay after various concentrations of $\operatorname{GLP}(0.313,0.625,1.25,2.5,5$ and $10 \mathrm{mg} / \mathrm{mL})$ inoculation. As shown in Figure 3A, the result indicated that GLP had significant inhibitory effects on cell viability of HCT-116 cells in a dose- and time-dependent manner. The inhibitory concentration of $50 \%\left(\mathrm{IC}_{50}\right)$ for 24,48 and $72 \mathrm{~h}$ were $9.25,5.72$ and $3.69 \mathrm{mg} / \mathrm{mL}$, respectively, and this range of concentration was chosen for further study. The inhibitory activity of GLP lasted for at least $72 \mathrm{~h}$. To exclude the possibility that the cytotoxicity of GLP on HCT-116 cells was applied by osmotic pressure, starch, a common polysaccharide produced by plants, was used as control. The results showed that starch $(0.313-10 \mathrm{mg} / \mathrm{mL})$ dose-dependently decreased cell growth, and 5-fluorouracil (5-FU) $(50 \mu \mathrm{g} / \mathrm{mL})$ 
dramatically suppressed cell viability (data not shown), suggesting the osmotic pressure within the range of concentrations of GLP did not obviously affect cell viability, and that GLP possessed cytotoxicity effects on HCT-116 cells. Figure 2B demonstrates that HCT-116 cells treated with GLP exhibited cellular morphological changes such as round sharp and volume reduction, and a concentration-dependent decrease in cellular number.

It is reported that Chinese herbs combined with adjuvant chemo- or/and radio-therapy may synergistically inhibit numerous cancers, significantly alleviate therapy side effects, improve quality of life, and prolong survival in cancer patients $[15,16]$. Our preliminary study was the first to report that the simultaneous treatment with GLP and 5-fluorouracil synergistically affects inhibitory and apoptotic effects on human colon cancer cells in vitro [17]. In theory, the anti-tumor effect of GLP was associated with its sub-fraction. Li et al. [18] reported that high molecular weight polysaccharides play an important role in cancer resistance, so GLP (molecular weight $>10 \mathrm{kDa}$ ) were studied for their anti-tumorogenic effects on HCT-116 cells.

Figure 3. Cytotoxicity of GLP on HCT-116 cells: (A) GLP suppressed the cell viability of HCT-116. Inhibitory rate was measured by MTT method. Starch-incubated cells were applied as control. Data represent means \pm SD of three independent experiments; and (B) Morphological changes in HCT-116 cells. After treatment with GLP, exfoliation of HCT-116 cells and naked areas were observed and captured under an inverted microscope $(\times 100)$. The arrows $(\uparrow)$ show naked areas without cells.

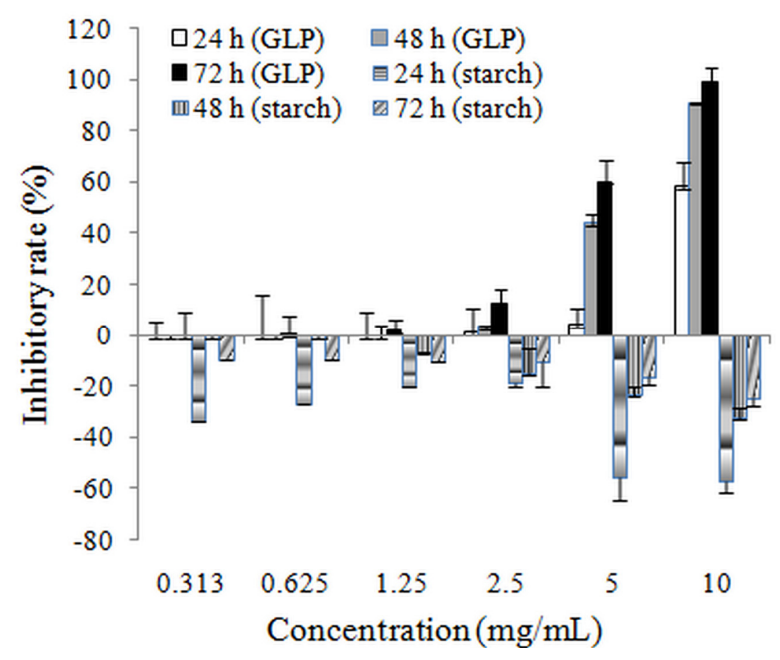

(A)

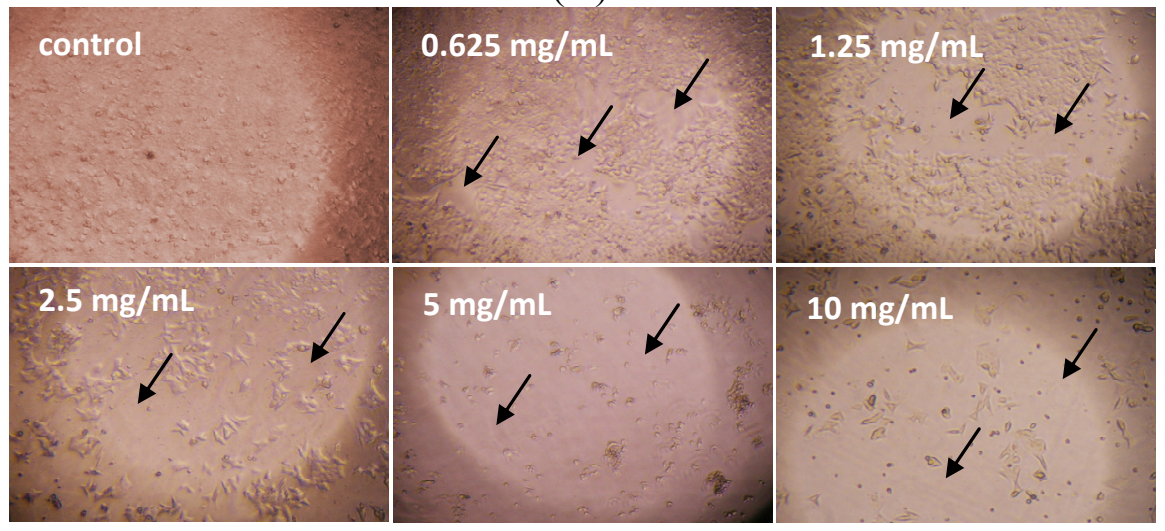

(B) 


\subsection{Effects of GLP on HCT-116 Cell Apoptosis}

As an important manner of cell death, apoptosis involves morphological changes with a series of stereotypy, DNA laddering fragments, phosphatidylserine eversion, and regulation of related factors and intracellular calcium concentration of cells [19]. DNA fragmentation has been found during GLP-mediated apoptosis in human leukemia HL-60 cells [20]. In the current study, we revealed that GLP directly induced HCT-116 apoptosis in vitro, as demonstrated by morphology, DNA gel electrophoresis and mitochondrial membrane potential. As shown in Figure 4A, cytoplasmic diffusion and cellular membrane integrity were observed in untreated cells. Clear signs of decreased cellular integrity accompanied by increased Hoechst 33,258 staining, are effects seen at GLP concentrations as low as $0.625 \mathrm{mg} / \mathrm{mL}$ after $48 \mathrm{~h}$. Cellular nuclei were clearly fragmented by increasing GLP concentration up to $10 \mathrm{mg} / \mathrm{mL}$. DNA ladder fragmentation was observed using agarose gel electrophoresis in human colon cancer cells incubated with 2.5 to $10 \mathrm{mg} / \mathrm{mL}$ GLP (Figure 4B). In Figure 4C,D, control cells appeared bright yellow with R123 staining. The R123 fluorescence of HCT-116 cells treated with GLP was weaker, and these effects were dose-dependent, indicating that those cells had damaged mitochondrial membrane integrity. Since these results in addition to $50 \mu \mathrm{g} / \mathrm{mL} 5$-FU can result in apoptosis on HCT-116 cells, it is implicated that GLP inhibits cell viability via an apoptotic pathway in human colon cancer cells.

Figure 4. Effects of GLP on apoptosis in HCT-116 cells. (A) Apoptotic cells measured by Hoechst 33,258 staining after treatment with GLP for $48 \mathrm{~h}$ under a fluorescence microscope $(\times 200)$. The arrows show cell fragments; (B) HCT-116 cells were exposed to the indicated concentrations of GLP for $24 \mathrm{~h}$. DNA was isolated and examined on $1.2 \%$ agarose gel; (C) Mitochondrial membrane potential $\left(\Delta \Psi_{\mathrm{m}}\right)$ was monitored by microscopy and photographed at each concentration of GLP; and (D) quantitative evaluation. Data are presented as mean $\pm \mathrm{SD}$. a, $p<0.01$ compared with control. $\mathrm{b}$, c and d, $p<0.01$ compared with $1.25,2.5$ and $5 \mathrm{mg} / \mathrm{mL}$ GLP treatment, respectively.

(A)

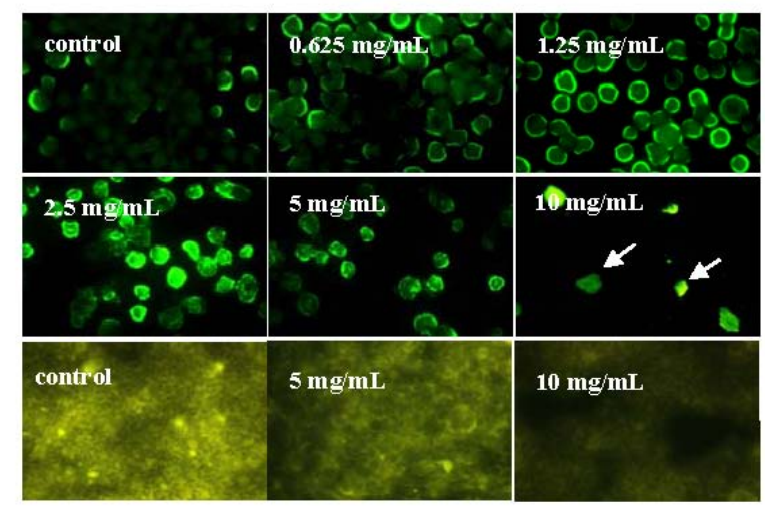

(D)

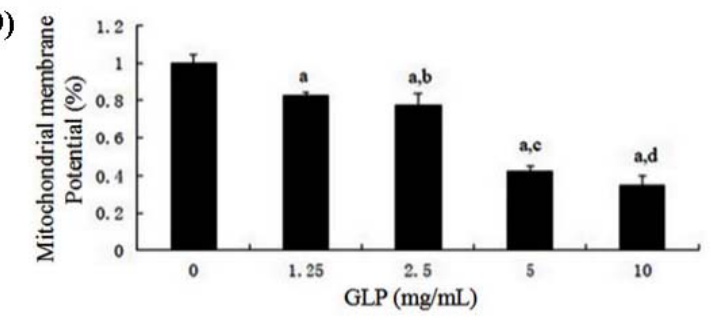

(B) $1052.5 \mathrm{M}(\mathrm{mg} / \mathrm{mL})$

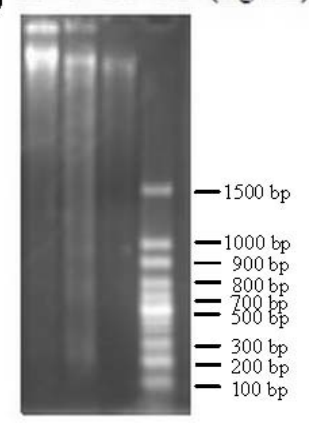




\subsection{Detection of Cell Cycle and Apoptosis by Flow Cytometry}

GLP-mediated apoptosis was confirmed by flow cytometry in HCT-116 cells. As shown in Figure 5, after $24 \mathrm{~h}$ of GLP exposure, apoptosis rates were boosted from $9.84 \%$ to $14.76 \%$ at 1.25 and $10 \mathrm{mg} / \mathrm{mL}$, respectively, with a maximum 10 -fold apoptosis rate compared to the untreated contrast at $1.47 \%$ $(p<0.01)$.

Cell cycle including at least 3 checkpoints $\left(G_{1} / S\right.$, intra-S-phase and $\left.G_{2} / M\right)$ has an essential role in regulating proliferation [21]. These checkpoints can enhance cell survival by limiting mutagenic events and decreasing abnormal heritable genetic changes following DNA damage [22]. Deregulated cell viability and suppressed cell death together provide the underlying opportunity for neoplastic progression [23]. Some anti-cancer agents can act as cell cycle blockers to interfere and switch cell cycle progression at a specific stage in cancer cells [24].

Figure 5 also shows that HCT-116 cells incubated with $1.25,2.5,5$ and $10 \mathrm{mg} / \mathrm{mL}$ GLP were significantly increased in S phase $(13.82 \%, 17.49 \%, 18.07 \%$ and $19.26 \%$, respectively). Compared with the control group (5.53\%), the percentage of GLP-treated cells in S phase significantly increased which was accompanied by a decrease in $\mathrm{G}_{1}$ and $\mathrm{G}_{2} / \mathrm{M}$ phase. The result was consistent with our previous results in a synergy trial of GLP and 5-FU [17]. Interestingly, GLP could arrest different cell cycle phases in other cancer cells. GLP has been reported to increase the percentage of $\mathrm{G}_{0} / \mathrm{G}_{1}$ in S180 ascitic tumor-bearing mice [25] and human leukemia THP-1 cells [26], indicating that the mechanisms of GLP-mediated apoptosis associated with cell cycle arrest are different.

Figure 5. Flow cytometry analysis of GLP-treated HCT-116 cells. Cells were incubated with GLP at various concentrations $(1.25-10 \mathrm{mg} / \mathrm{mL})$ for $24 \mathrm{~h}$ and then were harvested for quantifying apoptosis and cell cycle phase by flow cytometry (Propidium Iodide (PI) staining). Apoptosis and S phase cell populations of GLP-treated group are significantly higher than in the control. The blue peak = apoptosis; the first red peak $=\mathrm{G} 1$; the second red peak $=\mathrm{G} 2$; hatched peak $=\mathrm{S}$.
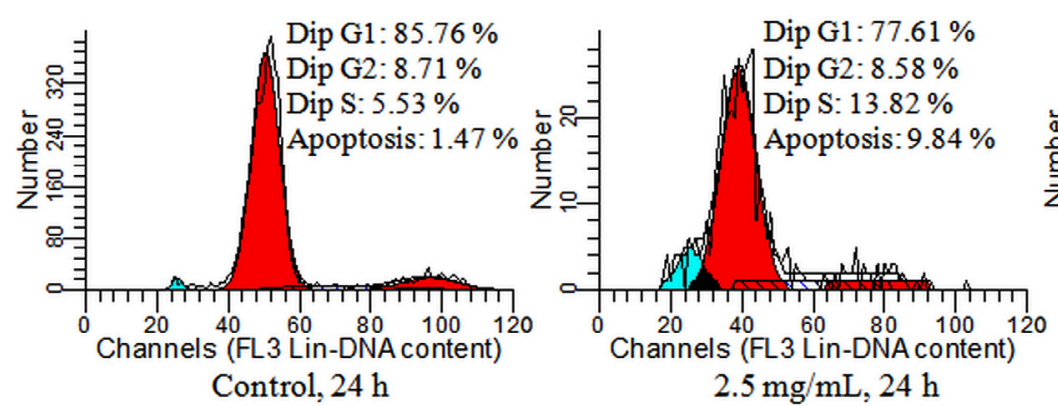

$2.5 \mathrm{mg} / \mathrm{mL}, 24 \mathrm{~h}$

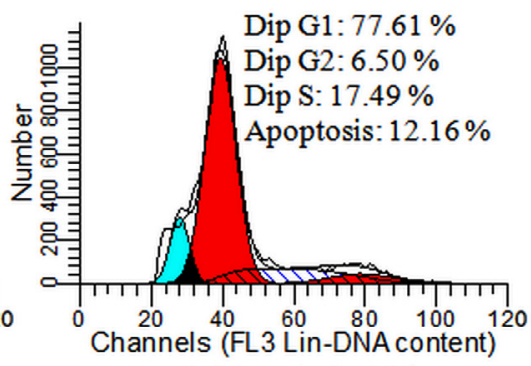

$1.25 \mathrm{mg} / \mathrm{mL}, 24 \mathrm{~h}$

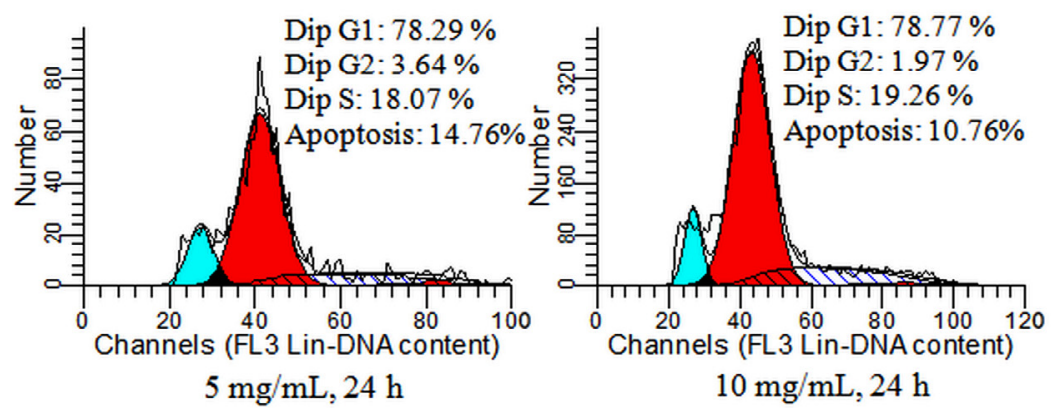




\subsection{Effects of GLP on the Mitogen-Activated Protein Kinase (MAPK) Pathway}

Components of the c-Jun $N$-terminal kinase (JNK), extracellular signal-regulated kinase (ERK) and p38 MAPK pathways are known to regulate the cell cycle, differentiation, growth and cell apoptosis [27]. The aim here was to determine whether GLP induced activation of ERK1/2, JNK and p38 in HCT-116 cells. As presented in Figure 6, the inhibitors of PD98059 and SB203580 did not affect cell growth. Twenty and $40 \mu \mathrm{mol} / \mathrm{L}$ SP600125 were able to partially protect human colon cells from GLP-treated cells with a significant decrease in cell viability $(p<0.05)$. This finding suggests that GLP could up-regulate JNK expression via the MAPK pathway to induce apoptosis in HCT-116 cells, whereas p38 and the ERK and MAPK pathway do not contribute to this process in HCT-116 cells.

Figure 6. Effects of mitogen-activated protein kinase (MAPK) inhibitors on GLP-induced HCT-116 cell death. Cells were treated in the absence or presence of different MAPK-specific inhibitors, $1 \mathrm{~h}$ prior to the addition of GLP, and then incubated in $5 \mathrm{mg} / \mathrm{mL}$ GLP for $12 \mathrm{~h}$. Cells were harvested to determine the percentage of viable cells as described in the Experimental section. A, $p<0.05$ compared with only $5 \mathrm{mg} / \mathrm{mL}$ GLP treatment group. Data expressed as mean \pm SD.
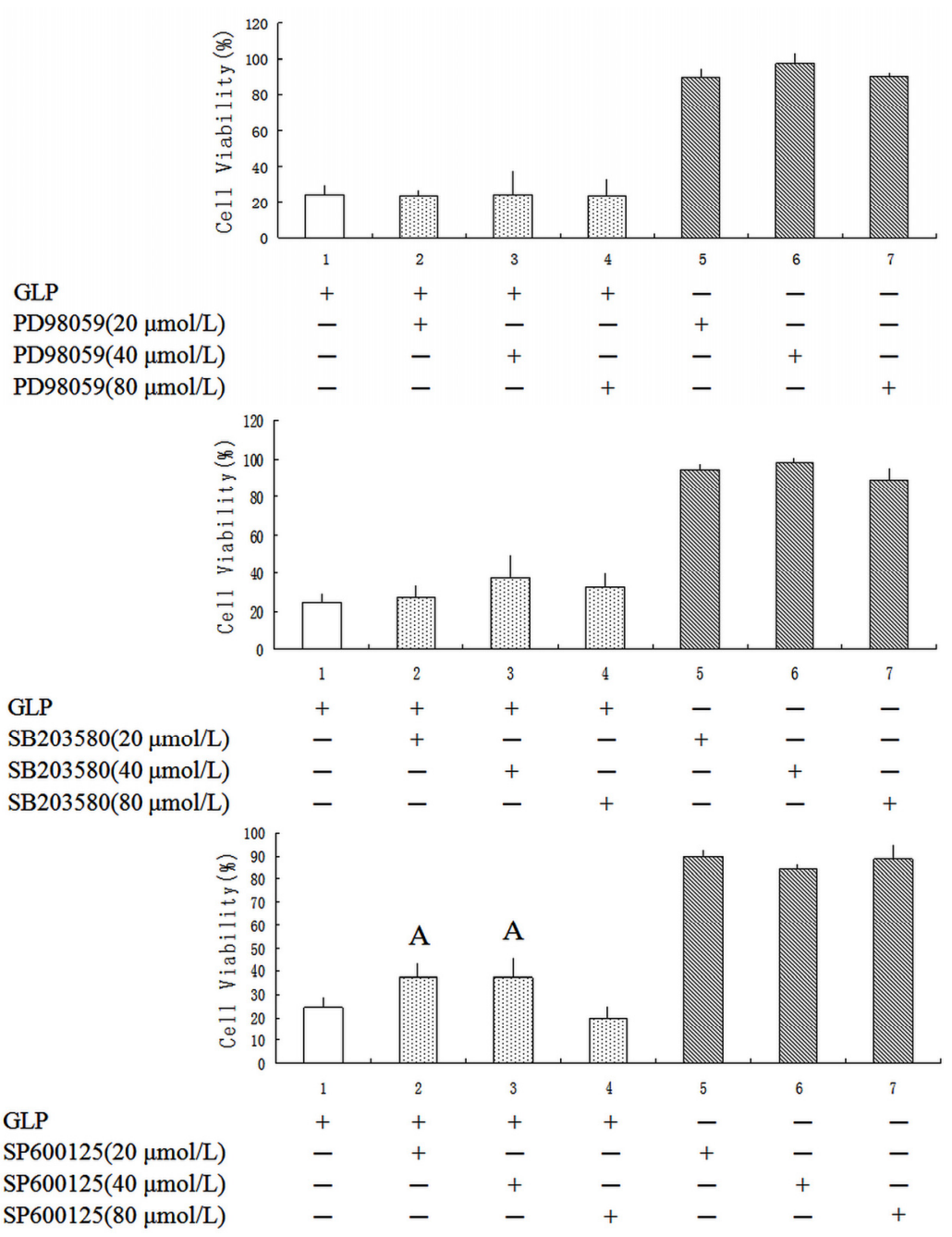


\subsection{Effects of GLP on Apoptosis-Related Proteins}

Mitochondria play a key role of mediator, and are an appropriate target for therapeutic agents for active control of cell death programs [28]. Once mitochondrial dysfunction, embodying such events as the opening of the mitochondrial permeability transition pore complex and depolarization of mitochondrial membrane potential $\left(\Delta \Psi_{\mathrm{m}}\right)$ has occurred, the intrinsic mitochondrial apoptotic pathway is initiated. Subsequently, caspases are activated and cell apoptosis is irreversible [29]. Some proteins in the mitochondrial pathway are related to control of cell apoptosis. The ratio of pro-apoptotic and anti-apoptotic proteins (Bax/Bcl-2) determines susceptibility of mitochondria-mediated apoptosis; cleavage of Poly (ADP-ribose) polymerase (PARP) facilitates cellular disintegration and is an important marker of cells undergoing apoptosis [30].

We found that loss of mitochondrial membrane potential was involved in GLP-mediated apoptosis of HCT-116 cells (Figure 4C,D). To determine the effects of the mitochondrial pathway on GLP-mediated apoptosis, caspase-3 and -9 activities were assessed. After HCT-116 cells were incubated with GLP for $24 \mathrm{~h}$, caspase-3 and -9 activities increased in a concentration-dependent manner (Figure 7A). These results suggest that caspases play a critical role in GLP-induced HCT-116 cell apoptosis. To further define HCT-116 apoptosis associated with caspase-dependent signal pathways, Western blotting was used to examine expression of Bax, Bcl-2, caspase-3, and PARP protein. As shown in Figure 7B, exposure of HCT-116 cells to $5 \mathrm{mg} / \mathrm{mL}$ GLP led to increasing levels of apoptotic Bax and caspase-3 in a dose-dependent manner. The expression of the anti-apoptotic Bcl-2 and PARP proteins were dose-dependently reduced by GLP exposure. The Bax:Bcl-2 ratio was increased from 0.15 to 1.48 . These results suggest that the caspase-dependent mitochondrial pathway performs a crucial function in GLP-induced apoptosis in HCT-116 cells. This is in agreement with other studies [31].

Figure 7. GLP induces cell apoptosis via caspase-dependent mitochondrial pathways. (A) Activity of caspases in GLP treated HCT-116 cells. A, $p<0.05$, and a, $p<0.01$ compared with control. b, $p<0.01$ compared with $2.5 \mathrm{mg} / \mathrm{mL}$ GLP treatment; (B) Western blot analyses of mitochondria pathway-related proteins. All bands were compared with the $\beta$-actin band and indicated as down-regulation (-) or up-regulation $(+)$; and $(\mathbf{C})$ Statistical analysis for western blot analysis.

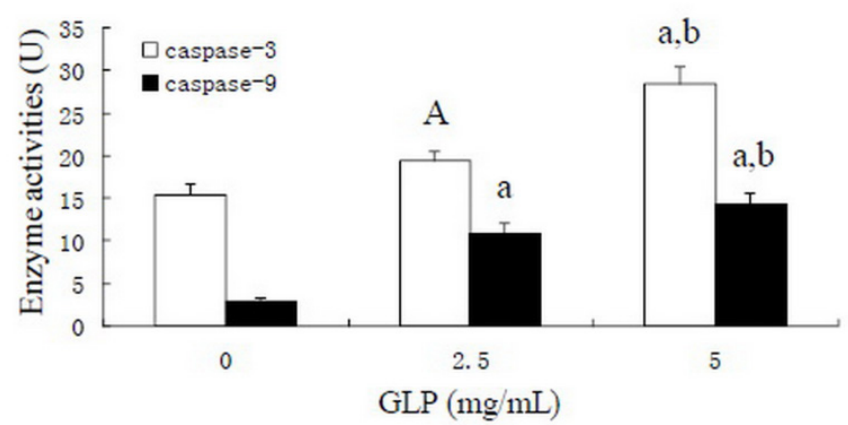

(A) 
Figure 7. Cont.

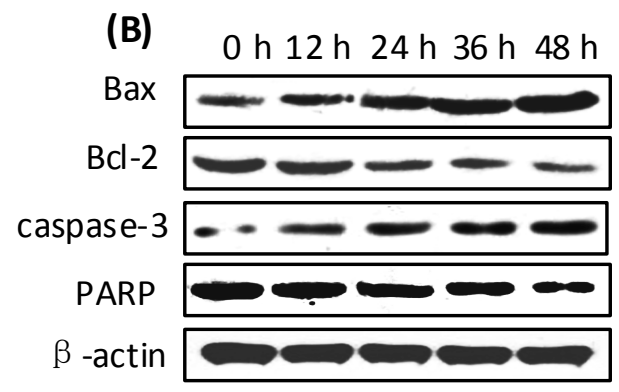

(C)

Percent change in protein expression

\begin{tabular}{lrrrr}
\hline & $12 \mathrm{~h}$ & $24 \mathrm{~h}$ & $36 \mathrm{~h}$ & $48 \mathrm{~h}$ \\
\hline Bax/Bcl-2 & +0.15 & +1.00 & +1.04 & +1.48 \\
caspase-3 & +0.12 & +0.20 & +0.29 & +0.35 \\
PARP & -0.10 & -0.19 & -0.30 & -0.41 \\
\hline
\end{tabular}

\section{Experimental Section}

\subsection{Materials}

Ganoderma lucidum was provided by the State Key Laboratory of Sub-health Intervention Technology, State Administration of Traditional Chinese Medicine (Changsha, China). Colon cancer cell line HCT-116 was obtained from Institute of Basic Medical Sciences (Beijing, China). Cells were grown in DMEM high glucose (Gibco, Grand Island, NY, USA) supplemented with 10\% FBS (Gibco) under $5 \% \mathrm{CO}_{2}$ at $37{ }^{\circ} \mathrm{C}$. MTT, Hoechst 33258 , caspase-3 and -9 activity assay kits were purchased from Beyotime, China. 5-Fluorouracil (5-FU, >99\% purity) was purchased from Shanghai Bangcheng Chemical Co., Ltd. (Shanghai, China). Inhibitors of JNK MAPK (SB203580), p38 MAPK (SP600125) and ERK MAPK (PD98059) were purchased from Biovision (Milpitas, CA, USA). The caspase-3, PARP, Bax, Bcl-2 and $\beta$-actin primary antibodies were purchased from Proteintech Group, USA; all other chemicals used were analytical grade unless stated otherwise.

\subsection{Isolation and Purification of GLP}

Slices of Ganoderma lucidum were dried at $60{ }^{\circ} \mathrm{C}$ and ground to a fine powder. The powder samples were refluxed in three volumes of methanol/chloroform solvent $(1: 2, v / v)$ and $80 \%$ ethanol three times for six-hour duration each time, respectively. After solution removal, dried residues were suspended in distilled water (residues: water $=1: 15, v / v$ ) following by vacuum filtration three times at $95{ }^{\circ} \mathrm{C}$ and $6 \mathrm{~h}$ for each time. The combined filtrates were concentrated with a vacuum rotary evaporator at $50{ }^{\circ} \mathrm{C}$. The concentrated solution was ethanol precipitated and then deproteinized using a Sevage assay. The extracts were purified using DEAE-Cellulose (DE 52), dialyzed, concentrated and freeze-dried. Ten milligram per milliliter GLP was ultrafiltered through membranes with molecular weight cut-off (MWCO) of 50, 30, 10 and 3 kDa (Millipore, Billerica, MA, USA) in an Amicon 8200 stirred cell (Millipore). The filtrate was concentrated and freeze-dried again. The dried powder was dissolved in DMEM culture medium (high glucose) supplemented with $10 \%$ FBS to get a stock solution of $10 \mathrm{mg} / \mathrm{mL}$, passed through $0.22 \mu \mathrm{m}$ filter and stored at $4{ }^{\circ} \mathrm{C}$ for subsequent analysis.

\subsection{Chemical Properties}

The yield of crude polysaccharide was measured as a percentage of the total weight of sample used. The polysaccharide content was calculated by the phenol-sulfuric acid method. After water-soluble polysaccharides were purified, GLP was ultrafiltered using membranes (Biomax-500, Biomax-300, 
Ultracel PL-100 and Ultracel PL-30) with MWCO of 3-50 kDa. The distribution of molecular weight was analyzed by weighing five freeze-dried fractions. Protein and nucleic acids were analyzed by UV spectrum. After GLP was hydrolyzed with $1 \mathrm{~mol} / \mathrm{L} \mathrm{H}_{2} \mathrm{SO}_{4}$ for $8 \mathrm{~h}$ at $100{ }^{\circ} \mathrm{C}$, the monosaccharide components were analyzed by high-performance anion exchange chromatography (HPAEC). The compounds of polysaccharide were identified by ultraviolet and infrared spectra.

\subsection{Cell Viability Assay}

MTT assay was used to evaluate the antiproliferative effects of GLP in HCT-116 cells. Cells were seeded at $3 \times 10^{4}$ cells/well in 96-well tissue culture plates and allowed to grow for $12 \mathrm{~h}$. The medium was replaced with fresh medium containing different concentrations of GLP (0.625 to $10 \mathrm{mg} / \mathrm{mL})$ for 24, 48 and $72 \mathrm{~h}$. At each time point, cells were added with $20 \mu \mathrm{L}$ MTT $(5 \mathrm{mg} / \mathrm{mL})$ solution and continued to incubate for $4 \mathrm{~h}$ at $37^{\circ} \mathrm{C}$. The resolution was removed, and $150 \mu \mathrm{L}$ DMSO was added to dissolve the formazan. Cells with starch $(0-10 \mathrm{mg} / \mathrm{mL})$ treatments were used as control and $50 \mu \mathrm{g} / \mathrm{mL}$ 5-FU was applied as positive control. Plates were observed to compare the colors of the resolution in the wells. Absorbance was read at $492 \mathrm{~nm}$ with Multiskan Microplate Reader (MK3, Thermo, Waltham, MA, USA).

\subsection{Hoechst 33258 Staining}

Apoptosis was determined by staining cells with Hoechst 33258 staining. Cells in $25 \mathrm{~cm}^{2}$ culture flasks were incubated with the indicated amounts of GLP or $50 \mu \mathrm{g} / \mathrm{mL} 5$-FU treated cells. Cells were washed with cold PBS and fixed with $2.5 \%$ glutaraldehyde for 10 min. After being washed with PBS twice, cells were incubated with $5 \mu \mathrm{g} / \mathrm{mL}$ Hoechst 33258 (Beyotime, Haimen, China) for $15 \mathrm{~min}$ at room temperature and then visualized under a fluorescence microscopy (Olympus, Tokyo, Japan).

\subsection{Measurement of DNA Fragmentation}

Apoptosis of cancer cells was detected for their DNA degradation by DNA gel electrophoresis analysis. Cells were treated with GLP $(2.5,5$ and $10 \mathrm{mg} / \mathrm{mL})$ or 5 -FU $(50 \mu \mathrm{g} / \mathrm{mL})$ for $24 \mathrm{~h}$. After two washes with PBS, cells were resuspended in $5 \mathrm{~mL}$ of $70 \%$ ethanol for $4 \mathrm{~h}$ at $-20{ }^{\circ} \mathrm{C}$ and centrifuged at $1000 \times g$ for $5 \mathrm{~min}$ at $4{ }^{\circ} \mathrm{C}$. The precipitate was dissolved in $40 \mu \mathrm{L}$ phosphate-citric acid buffer, $\mathrm{pH} 7.8$, and incubated for $45 \mathrm{~min}$ at room temperature with intermittent shaking. The solution was centrifuged at $1500 \times \mathrm{g}$ for $5 \mathrm{~min}$. The supernatant was collected using a new tube, mixed with $3 \mu \mathrm{L}$ of $1 \mathrm{mg} / \mathrm{mL}$ RNaseA and $3 \mu \mathrm{L}$ of $0.25 \% \mathrm{NP} 40$, and then incubated at $37^{\circ} \mathrm{C}$ for $30 \mathrm{~min}$. DNA fragmentation was then analyzed by gel electrophoresis on a $1.2 \%$ agarose gel.

\subsection{Mitochondrial Membrane Potential Analysis}

After treatment with GLP $(0,1.25,2.5,5$ and $10 \mathrm{mg} / \mathrm{mL})$ for $24 \mathrm{~h}$, cells were washed with PBS twice and incubated with $8 \mu \mathrm{M}$ rhodamine123 (R123) at $37{ }^{\circ} \mathrm{C}$ for $30 \mathrm{~min}$ in the dark. Cells were washed two times again. Cells treated with $50 \mu \mathrm{g} / \mathrm{mL} 5$-FU served as a positive control. The intensity of fluorescence was observed under a fluorescence microscope (Olympus, Tokyo, Japan) and 
measured using a fluorometric plate reader (Corning, Corning, NY, USA) equipped with a Scientific Varioskan Flash (Thermo) at an excitation wavelength of $495 \mathrm{~nm}$ and an emission wavelength of $530 \mathrm{~nm}$.

\subsection{Caspase Activity Assay}

Caspase- 3 and -9 activities in cells were determined by the cleavage of colorimetric caspase substrates, Ac-DEVD- $p$ NA and Ac-LEHD- $p$ NA, using the caspase-3 and -9 activity kits (Beyotime, China). In brief, HCT-116 cells were treated with $0,2.5$ and $5 \mathrm{mg} / \mathrm{mL}$ GLP for $24 \mathrm{~h}$ in 6 -well plates. After centrifugation, cells were lysed on ice for $15 \mathrm{~min}$. The cells were centrifuged at $10,000 \times g$ for 20 min at $4{ }^{\circ} \mathrm{C}$ and the supernatants were then transferred to 96-well microtiter plates. Assays were determined by incubating $10 \mu \mathrm{L}$ protein of cell lysate in $80 \mu \mathrm{L}$ reaction buffer $(1 \% \mathrm{NP}-40,20 \mathrm{mM}$ Tris- $\mathrm{HCl}, \mathrm{pH} 7.5,137 \mathrm{mM} \mathrm{NaCl}$ and $10 \%$ glycerol) and $10 \mu \mathrm{L}$ of $2 \mathrm{mM}$ substrate. After incubation for $2 \mathrm{~h}$ at $37{ }^{\circ} \mathrm{C}$, the absorbance of cleavage ( $p$ NA) was quantified with Multiskan Microplate Reader (MK3, Thermo, USA) at $405 \mathrm{~nm}$.

\subsection{Flow Cytometry}

Cells $\left(1 \times 10^{6}\right)$ were seeded into 6-well culture plates. After treatment with GLP for 24 and $48 \mathrm{~h}$, cells were washed three times with PBS. The cells were then fixed overnight in $70 \%$ ethanol. After overnight incubation at $4{ }^{\circ} \mathrm{C}$, cells were rehydated in PBS for $30 \mathrm{~min}$ and subsequently stained with dye liquid (1 g/L sodium citrate, $1 \mathrm{mg} / \mathrm{L}$ RNase A, $50 \mathrm{mg} / \mathrm{L}$ propidium iodide, $10 \mathrm{~g} / \mathrm{L}$ Triton X-100) at $4{ }^{\circ} \mathrm{C}$ for $30 \mathrm{~min} .50 \mu \mathrm{g} / \mathrm{mL} 5$-FU was used as a positive control. The apoptosis rate and cell cycle was analyzed by an FC500 flow cytometer (Beckman Coulter Inc., Miami, FL, USA).

\subsection{MAPK Inhibitors Assay}

To investigate the effects of MAPK inhibitors on eliciting apoptotic GLP-treated cancer cells, MAPK inhibitors including PD98059 (ERK specific inhibitor), SB203580 (JNK specific inhibitor) and SP600125 (p38 specific inhibitor) at concentrations of 20, 40 and $80 \mu \mathrm{mol} / \mathrm{L}$ were introduced to cells and cultivated for $1 \mathrm{~h}$ after seeding cells $\left(3 \times 10^{3}\right.$ cells/well $)$ in 96 -well culture plates for $24 \mathrm{~h}$. Subsequently, $5 \mathrm{mg} / \mathrm{mL}$ GLP was added, and samples were incubated for $24 \mathrm{~h}$ at $37^{\circ} \mathrm{C}$. At the end of the assay, the cells were estimated using the Multiskan Microplate Reader at $490 \mathrm{~nm}$.

\subsection{Western Blot Analysis}

Cells were treated with $5 \mathrm{mg} / \mathrm{mL}$ GLP for $0,12,24,36$ and $48 \mathrm{~h}$, and then lysed in RIPA lysis buffer (Applygen, Beijing, China) (50 mM Tris, pH 7.4, $150 \mathrm{mM} \mathrm{NaCl}, 1 \%$ Triton X-100, 1\% sodium deoxycholate, $0.1 \%$ SDS, sodium orthovanadate, sodium fluoride, EDTA, leupeptin) on ice for $30 \mathrm{~min}$. After centrifugation at $12,000 \mathrm{rpm}$, proteins were measured by the Bio-Rad Bradford assay with bicinchoninic acid (BCA) as the standard, separated by a 10\%-12\% SDS-PAGE and transferred onto $0.45 \mu \mathrm{m}$ polyvinylidene fluoride (PVDF) membranes (Millipore, Billerica, MA, USA) according to the methods as described [32]. The membranes were blocked in $5 \%$ non fat milk in TBS $(10 \mathrm{mmol} / \mathrm{L}$ Tris- $\mathrm{HCl}, \mathrm{pH} 7.5$ and $150 \mathrm{mmol} / \mathrm{L} \mathrm{NaCl}$ ) containing $0.1 \%$ Tween (TBST) for $1 \mathrm{~h}$ at room temperature followed by incubation overnight at $4{ }^{\circ} \mathrm{C}$ with the chosen primary antibodies, including $\beta$-actin 
(1:4000), caspase-3 (1:500), PARP (1:800), Bax (1:800) and Bcl-2 (1:800). The membrane was washed with TBST three times, and the proteins were labeled using horseradish peroxidase-conjugated goat anti-rabbit or anti-mouse secondary antibody (1:3000) and enhanced using ECL system (Thermo Scientific Pierce, Waltham, MA, USA). The bands were visualized by exposure on X-OMAT BT films (Fujifilm, Tokyo, Japan). The films were scanned and densitometric analyses were performed using ImageJ software (National Institutes of Health, Bethesda, MD, USA).

\subsection{Statistical Analysis}

All calculations were performed with SPSS 18.0 for Windows (SPSS, Chicago, IL, USA). All data are expressed as means $\pm \mathrm{SD}$. The significance of differences among groups was analyzed using one-way ANOVA followed by Bonferroni's test for multiple-comparison or Student's $t$ test, with significance at $p<0.05$ and extreme significance at $p<0.01$.

\section{Conclusions}

In summary, our study provides significant insight into the cytotoxicity and apoptosis inducing ability of GLP in human colon cancer HCT-116 cells. Raising the Bax/Bcl-2-ratio triggered the apoptotic process though mitochondria-mediated caspase-dependent intrinsic pathway, involving depolarization of mitochondrial membrane. With the addition of GLP treatment, the MAPK signaling pathway and cell cycle arrest at S phase is also attributed to apoptosis in HCT-116 cells. These data provide evidence for the possible mechanism of GLP-mediated apoptosis. However, other signaling pathways such as TNF, Fas, P53 pathway might also be involved in GLP-mediated apoptosis and it is not yet clear whether there is a similar tendency in animal models or clinical studies.

\section{Acknowledgments}

We are grateful to Dongbo Liu and Zhilan Xia for providing section of Ganoderma lucidum, and Xianzhou Nie and Dickison Virginia for critically reviewing the manuscript.

\section{Author Contributions}

Xingyao Xiong, Youjin Yi, Rencai Wang and Zengenni Liang conceived and designed the study. Zengenni Liang, Yutong Guo and Qiulong Hu performed the experiments. Zengenni Liang wrote the paper. Xingyao Xiong, Rencai Wang, and Youjin Yi reviewed and edited the manuscript. All authors read and approved the manuscript.

\section{Conflicts of Interest}

The authors declare no conflict of interest. 


\section{References}

1. Atkin, W.S.; Edwards, R.; Kralj-Hans, I.; Wooldrage, K.; Hart, A.R.; Northover, J.M.; Parkin, D.M.; Wardle, J.; Duffy, S.W.; Cuzick, J. Once-only flexible sigmoidoscopy screening in prevention of colorectal cancer: A multicentre randomised controlled trial. Lancet 2010, 375, 1624-1633.

2. Cutsem, E.V.; Nordlinger, B.; Cervantes, A. Advanced colorectal cancer: ESMO clinical practice guidelines for treatment. Ann. Oncol. 2010, 21, 93-97.

3. Siegel, R.; Desantis, C.; Virgo, K.; Stein, K.; Mariotto, A.; Smith, T.; Cooper, D.; Gansler, T.; Lerro, C.; Fedewa, S.; et al. Cancer treatment and survivorship statistics, 2012. CA Cancer J. Clin. 2012, 62, 220-241.

4. Siegel, R.; Naishadham, D.; Jemal, A. Cancer statistics, 2012. CA Cancer J. Clin. 2012, 62, 10-29.

5. Wong, R.S. Apoptosis in cancer: From pathogenesis to treatment. J. Exp. Clin. Cancer Res. 2011, 30, 87-100.

6. Kim, K.N.; Heo, S.J.; Kang, SM.; Ahn, G.; Jeon, Y.J. Fucoxanthin induces apoptosis in human leukemia HL-60 cells through a ROS-mediated Bcl-xL pathway. Toxicol in Vitro 2010, 24, 1648-1654.

7. Sykiotis, G.P.; Papavassiliou, A.G. Apoptosis: The suicide solution in cancer treatment and chemoprevention. Expert Opin. Investig. Drug 2006, 15, 575-577.

8. Huerta, S.; Goulet, E.J.; Livingston, E.H. Colon cancer and apoptosis. Am. J. Surg. 2006, 191, $517-526$.

9. Chen, X.P.; Wang, W.X.; Li, S.B.; Xue, J.L.; Fan, L.J.; Sheng, Z.J.; Chen, Y.G. Optimization of ultrasound-assisted extraction of Lingzhi polysaccharides using response surface methodology and its inhibitory effects on cervical cancer cells. Carbohydr. Polym. 2010, 80, 944-948.

10. Xu, Z.T.; Chen, X.P.; Zhong, Z.F.; Chen, L.D.; Wang, Y.T. Ganoderma lucidum polysaccharides: Immunomodulation and potential anti-tumor activities. Am. J. Chin. Med. 2011, 39, 15-27.

11. Sun, L.X.; Lin, Z.B.; Li, X.J.; Li, I.; Lu, J.; Duan, X.S.; Ge, Z.H.; Song, Y.X.; Xing, E.H.; $\mathrm{Li}$, W.D. Promoting effects of Ganoderma lucidum polysaccharides on B16F10 cells to activate lymphocytes. Basic Clin. Pharmacol. 2011, 108, 149-154.

12. Li, F.L.; Zhang, Y.M.; Zhong, Z.J. Antihyperglycemic effect of Ganoderma lucidum polysaccharides on streptozotocin-induced diabetic mice. Int. J. Mol. Sci. 2011, 12, 6135-6145.

13. Li, S.G.; Zhang, Y.Q. Characterization and renal protective effect of a polysaccharide from Astragalus membranaceus. Carbohydr. Polym. 2009, 78, 343-348.

14. Xu, L.; Li, H.G.; Xu, Z.Y.; Wang, Z.Q.; Liu, L.S.; Tian, J.H.; Sun, J.; Zhou, L.; Yao, Y.; Jiao, L.; et al. Multi-center randomized double-blind controlled clinical study of chemotherapy combined with or without traditional Chinese medicine on quality of life of postoperative non-small cell lung cancer patients. BMC Complement. Altern. Med. 2012, 12, 112.

15. Chan, K.K.; Yao, T.J.; Jones, B.; Jones, J.F.; Zhao, F.K.; Leung, C.Y.; Lau, S.K.; Yip, M.W.; Ngan, H.Y. The use of Chinese herbal medicine to improve quality of life in women undergoing chemotherapy for ovarian cancer: A double-blind placebo-controlled randomized trial with immunological monitoring. Ann. Oncol. 2011, 22, 2241-2249.

16. Lam, W.; Bussom, S.; Guan, F.; Jiang, Z.; Zhang, W.; Gullen, E.A.; Liu, S.H.; Cheng, Y.C. The four-herb Chinese medicine PHY906 reduces chemotherapy-induced gastrointestinal toxicity. Sci. Transl. Med. 2010, 2, 45-59. 
17. Liang, Z.; Yi, Y.J.; Guo, Y.T.; Wang R.C.; Xiong, X.Y. Effect of combined Ganoderma lucidum polysaccharides and fluorouracil on proliferation and apoptosis in human colon carcinoma HCT-116 cells. Food Sci. 2012, 33, 310-314.

18. Li, Y.Q.; Fang, L.; Zhang, K.C. Structure and bioactivities of a galactose rich extracellular polysaccharide from submergedly cultured Ganoderma lucidum. Carbohydr. Polym. 2008, 77, 323-328.

19. Ram, V.J.; Kumari, S. Natural products of plant origin as anticancer agents. Drug News Perspect. 2001, 14, 465-482.

20. Hu, Q.P.; Xu, J.G. Active components and antimicrobial activity in two Sedum species grown in Shanxi Huoshan, China. J. Food Agric. Environ. 2012, 10, 172-174.

21. Dai, Y.; Grant, S. New insights into checkpoint kinase 1 in the DNA damage response signaling network. Clin. Cancer Res. 2010, 16, 376-383.

22. Kuerbitz, S.J.; Plunkett, B.S.; Waklsh, W.V.; Kastan, M.B. Wild-type p53 is a cell cycle checkpoint determinant following irradiation. Proc. Natl. Acad. Sci. USA 1992, 89, 7491-7495.

23. Evan, G.I.; Vousden, K.H. Proliferation, cell cycle and apoptosis in cancer. Nature 2001, 411, 342-348.

24. Ahcene, B.; Xavier, R.; Jean, B. Chalcones derivatives acting as cell cycle blockers: Potential anti cancer drugs? Curr. Drug Targets 2009, 10, 363-371.

25. Li, J.J.; Lei, L.S.; Yu, C.L.; Zhu, Z.G.; Zhang, Q.; Wu, S.G. Effect of Ganoderma lucidum polysaccharides on tumor cell nucleotide content and cell cycle in S180 ascitic tumor-bearing mice. J. South Med. Univ. 2007, 27, 1003-1005.

26. Hsu, J.W.; Huang, H.C.; Chen, S.T.; Wong, C.H.; Juan, H.F. Ganoderma lucidum polysaccharides induce macrophage-like differentiation in human leukemia THP-1 cells via caspase and p53 activation. Evid-Based Complement. Altern. 2011, 2011, 1-13.

27. Tidyman, W.E.; Rauen, K.A. The RASopathies: Developmental syndromes of Ras/MAPK pathway dysregulation. Curr. Opin. Genet. Dev. 2009, 19, 230-236.

28. Olson, M.; Kornbluth, S. Mitochondria in apoptosis and human disease. Curr. Mol. Med. 2001, 1, 91-122.

29. Sharma, S.; Singh, R.L.; Kakkar, P. Modulation of Bax/Bcl-2 and caspases by probiotics during acetaminophen induced apoptosis in primary hepatocytes. Food Chem. Toxicol. 2011, 49, 770-779.

30. Soldani, C.; Scovassi, A.I. Poly(ADP-ribose) polymerase-1 cleavage during apoptosis: An update. Apoptosis 2002, 7, 321-328.

31. Shang, D.J.; Li, Y.; Wang, C.; Wang, X.M.; Yu, Z.; Fu, X.A. Novel polysaccharide from Se-enriched Ganoderma lucidum induces apoptosis of human breast cancer cells. Oncol. Rep. 2011, 25, 267-272.

32. Bartels, T.; Choi, J.G.; Selkoe, D.J. $\alpha$-Synuclein occurs physiologically as a helically folded tetramer that resists aggregation. Nature 2010, 477, 107-110.

(C) 2014 by the authors; licensee MDPI, Basel, Switzerland. This article is an open access article distributed under the terms and conditions of the Creative Commons Attribution license (http://creativecommons.org/licenses/by/3.0/). 